\title{
UTILIZANDO A FILOSOFIA LEAN PARA REDUZIR O LEAD TIME DE SERVIÇOS DE UMA ASSISTÊNCIA TÉCNICA NO RIO DE JANEIRO
}

\author{
Leandro Alves Nascimento \\ Universidade do Grande Rio José Souza Herdy - UNIGRANRIO \\ Endereço Corporativo \\ leandronascimento@unigranrio.br \\ Leonardo Aragão Guimarães \\ Universidade do Grande Rio José Souza Herdy - UNIGRANRIO \\ Endereço Corporativo \\ professorleo@unigranrio.edu.br
}

\begin{abstract}
RESUMO
Este estudo de caso apresenta os resultados de como a filosofia Lean contribuiu para que em uma empresa prestadora de serviços a uma rede de serviços autorizada multinacional conseguisse reagir ao mercado com altos lead times dos pedidos no atendimento aos serviços prestados aos seus consumidores. Num cenário de turbulência financeira e com um alto índice de orçamentos rejeitados, a empresa solicitou aos autores do artigo um projeto de melhoria. Através do mapeamento do fluxo de valor foram identificados os desperdícios ao longo do processo, onde, a causa-potencial foi priorizada com a análise de Pareto. O desdobramento desta análise acarretou na descoberta da causa-raiz identificada como o tempo de processamento de pedidos do fornecedor da rede de serviços. A solução proposta para este problema foi a utilização do milk run para compra de peças nos fornecedores adjacentes onde foi possível ajustar o lead time do serviço de 25 dias para 4 dias de acordo com a perspectiva do cliente. Com isso, os índices de orçamentos rejeitados diminuíram de 27\% para 14\% proporcionando uma melhoria do processo da empresa e, consequentemente, uma saída do cenário dispendioso na qual se encontrava.
\end{abstract}

Palavra-chave: Filosofia Lean; Pensamento Enxuto; Milk Run; Gestão de Serviços.

\begin{abstract}
This case study presents the results of Lean philosophy that has contributed to an international communication network service company committing itself to react to the market with high response times to requests for services provided to its consumers. In a scenario of financial turmoil and with a high rate of rejected budgets, a proposal was requested from the authors of an improvement project article. Through the mapping of the value stream, the procedures were identified throughout the process, where a potential cause was previously analyzed with a Pareto analysis. The breakdown of data analysis into rootidentified existence as the order processing time of the service provider. The proposed solution to this problem was to use the milk run to purchase parts from one of the adjacent suppliers where it was possible to use the timeframe from 25 days to 4 days from a customer
\end{abstract}


perspective. This making the quality of provision of the value of the company and consequently an exit from the costly scenario in which it found itself.

Keywords: Lean philosophy; Lean Thinking; Milk Run; Service management.

\section{Como Citar:}

NASCIMENTO, Leandro Alves; GUIMARÃES, Leonardo Aragão. Utilizando a filosofia lean para reduzir o lead time de serviços de uma assistência técnica no rio de janeiro. In: SIMPÓSIO DE PESQUISA OPERACIONAL E LOGÍSTICA DA MARINHA, 19., 2019, Rio de Janeiro, RJ. Anais [...]. Rio de Janeiro: Centro de Análises de Sistemas Navais, 2019.

\section{INTRODUÇÃO}

A evolução do comercio internacional tornou cada vez mais dinâmico o acesso a bens e serviços por preços, em geral, mais acessíveis, de acordo com o patamar dos consumidores, que por sua vez, avaliam as ofertas disponíveis no mercado em termos de preço, qualidade e serviço que podem variar da disponibilidade de bens até o serviço pósvenda (CORRÊA \& CORRÊA, 2017).

Em busca da adequação a essas mudanças algumas empresas são levadas a recorrerem a metodologias que tornem possível o aperfeiçoamento de seus processos de modo que se mantenham no mercado (Snee, 2010). Deste modo, utiliza-se a filosofia lean como estratégia para elevar a qualidade das operações (WERKEMA, 2006).

Para Corrêa \& Corrêa (2017), entre os pontos críticos que dificultam empresas de serviços na prestação de atendimentos com qualidade estão: (i) o relacionamento com os fornecedores; (i) atrasos na entrega de materiais; (iii) processos de apoio confusos e os transbordos da capacidade de entrega. Logo, é diligente agregar ao planejamento do negócio estratégias voltadas a qualidade que resultem em excelência operacional. (DeFOE \& JURAN, 2015).

\subsection{OBJETIVO}

O objetivo deste projeto é mitigar o tempo de atendimento de uma empresa prestadora de serviços, utilizando a filosofia lean para reduzir a variabilidade e aumentar a velocidade dos serviços prestados. Deste modo, espera-se que sejam atingidas as expectativas dos clientes, desenvolvendo para a empresa uma nova perspectiva de valor e de vantagens competitivas.

\section{FUNDAMENTAÇÃO TEÓRICA}

\subsection{LEAN MANUFACTURING}

O termo lean, que significa enxuto ou esbelto, é baseado no Sistema Toyota de Produção (também conhecido pela sua sigla em inglês TPS - Toyota Production System). O termo lean foi cunhado no livro "A máquina que mudou o mundo" por Womack, Jones e Ross (1990) para definir um sistema de produção mais eficiente, flexível, ágil e inovador para enfrentar um mercado em constante mudança (GUIMARÃES \& GUIMARÃES, 2016). 
Womack \& Jones (2004) definem Lean Thinking (pensamento enxuto) como um antídoto ao que não agrega valor para o cliente por estabelecer uma sequência lógica de ações que mantém o fluxo sem interrupções, contribuindo de forma contínua para operações cada vez mais eficazes. A figura 1 apresenta os cinco passos do pensamento enxuto:

\begin{tabular}{|c|c|c|c|c|}
\hline VALOR & $\begin{array}{c}\text { FLUXO DE } \\
\text { VALOR }\end{array}$ & $\begin{array}{c}\text { FLUXO } \\
\text { CONTÍNUO }\end{array}$ & PUXAR & PERFEIÇÃO \\
\hline $\begin{array}{l}\text { Delimitar pela } \\
\text { voz do cliente o } \\
\text { que é valor }\end{array}$ & $\begin{array}{c}\text { Alinhar } \\
\text { sequencialmente as } \\
\text { atividades que } \\
\text { geram esse valor }\end{array}$ & $\begin{array}{l}\text { Executar essas } \\
\text { atividades de } \\
\text { forma contínua }\end{array}$ & $\begin{array}{l}\text { toda vez que o } \\
\text { cliente solicitar }\end{array}$ & $\begin{array}{l}\text { Buscando } \\
\text { sempre a } \\
\text { efetividade }\end{array}$ \\
\hline
\end{tabular}

Figura 1 - Os cinco passos do Lean Thinking

Fonte: Adaptado por Womack \& Jones (2004)

Para compreensão da filosofia enxuta é importante destacar o termo desperdício, que neste assunto possui uma conotação singular subordinada ao valor percebido pelos clientes em suas necessidades, desejos e expectativas (Ohno, 1997). Para Costa e Jardim (2010) uma forma de identificar os desperdícios é se pondo no lugar do cliente e refletir criticamente sob a operação na busca da redução dos tempos das atividades que não agregam valor.

Os 7 desperdícios são classificados como: (1) superprodução, (2) transporte de materiais que não agregam valor, (3) processamento demasiado, (4) produtos defeituosos, (5) estoques em excesso de trabalho em processamento, (6) movimentação de recursos que não geram receita e (7) espera, seja do cliente ou uma fila para produção.

Liker (2005) acrescenta ainda o desperdício de intelecto humano como o oitavo desperdício da proposta original de Ohno (1997). A eliminação completa desses desperdícios levará a operação a uma margem de eficiência bem ampla garantindo maior velocidade na entrega dos produtos aos clientes e aumentando o fluxo de caixa da empresa perante cenários dispendiosos (COSTA \& JARDIM, 2010).

\subsection{O MAPEAMENTO DO FLUXO DE VALOR}

O Value Stream Map (VSM), traduzido como mapeamento do fluxo de valor (MFV) é a ferramenta lean destinada a mapear o quadro atual do processo analisado e, posteriormente, é traçado o mapa do estado futuro desejado (Rother \& Shock, 2004).

No VSM destacam-se os seguintes elementos: o fluxo de materiais, a transformação de matéria prima ao produto acabado e o fluxo de informações que direciona todas as atividades envolvidas no processo de produção ou serviço até o cliente (LACERDA; XAMBRE; ALVELOS, 2016).

Para estabelecer este fluxo o primeiro passo é mapear as atividades relacionando o recurso, o processo e a duração com o foco no cliente, para diferenciar quais informações são realmente produtivos e quais atividades deste fluxo devem ser imediatamente eliminadas (PIAZZA; CECCONELLO; VIDOR, 2016). 
A figura 2 apresenta as etapas da criação do VSM do estado atual até a implementação das melhorias para atingir o estado futuro:

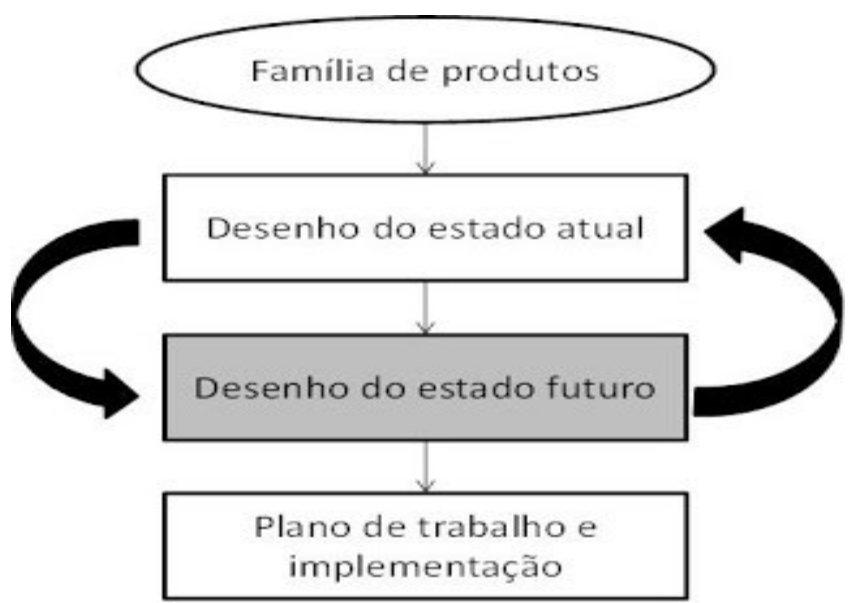

Figura 2 - Etapas iniciais do mapeamento do fluxo de valor Fonte: ROTHER \& SHOCK (2004).

Conforme Lacerda; Xambre; Alvelos (2016) para o desenvolvimento do MFV é necessário o uso de métricas para analisar a duração das atividades e o resultado do processo analisado. A tabela 1 conceitua as métricas usadas para o desenvolvimento do MFV no estudo de caso:

\begin{tabular}{|c|c|c|}
\hline Métrica & Medição & Definição \\
\hline RTY & Ao final do processo & $\begin{array}{l}\text { RTY - Rolled Throughput Yield - É uma } \\
\text { medida de rendimento global que } \\
\text { considera o impacto do refugo e do } \\
\text { retrabalho (Campos, 2014). }\end{array}$ \\
\hline Lead time $(\mathrm{LT})$ & A o final do processo & $\begin{array}{l}\text { Tempo estimado entre a solicitação do } \\
\text { serviço até sua entreg a ao cliente } \\
\text { (WERKEMA, 2006) }\end{array}$ \\
\hline Taxa de s aid a & Ao final do processo & $\begin{array}{l}\text { Resultado de um processo ao decorrer do } \\
\text { periodo de terpo definido (SLACK, } 2015 . \\
\text { ROTHER \& SHOCK, 2004). }\end{array}$ \\
\hline $\begin{array}{l}\text { Tempo de ciclo } \\
\text { (TC) }\end{array}$ & Por atividades & $\begin{array}{l}\text { É o tempo necessário para conclusão de } \\
\text { uma atividade (Corrêa \& Corrêa, 2004) }\end{array}$ \\
\hline Takt time & $\begin{array}{l}\text { Ao final do processo } \\
\text { de acordo com VOC }\end{array}$ & $\begin{array}{l}\text { Tempo que o cliente estima para a execução } \\
\text { do serviço (WERKEMA, 2006). }\end{array}$ \\
\hline $\begin{array}{l}\text { Tempo que } \\
\text { agrega valor } \\
\text { (TA V) }\end{array}$ & A o final do processo & $\begin{array}{l}\text { Tempo de execução da tarefa que agrega } \\
\text { valor e que o cliente está disposto a pag ar } \\
\text { (OHNO, 1997. WOMACK \& JONES, 2004). }\end{array}$ \\
\hline $\begin{array}{l}\text { Eficiência do } \\
\text { ciclo do } \\
\text { processo }\end{array}$ & A o final do processo & $\begin{array}{l}\text { Indicador que mede a relação entre TA V e o } \\
\text { LT (WERKEMA, 2006). }\end{array}$ \\
\hline
\end{tabular}

Tabela 1 - Métricas lean utilizadas no estudo de caso

Fonte: adaptado de Werkema (2006)

Para Fast (2016), a maioria das empresas reportam apenas os resultados dos processos deixando de analisar como os recursos fluem dentro da operação, seja na indústria de bens ou de serviços, sem indicar o impacto financeiro de retrabalhos. Segundo Gibbons \& Burgess (2010) a métrica que melhor expressa essa relação é o RTY por reportar o efeito acumulativo do processo em suas principais entregas ao cliente. 


\subsection{GRÁFICO DE PARETO}

Campos (2014) define o gráfico de Pareto como um poderoso método de análise que permite fragmentar grandes problemas em pequenas partes, classificá-las e priorizá-las de acordo com fatos e dados separando os pouco vitais dos muitos triviais. Sendo assim, $80 \%$ das oportunidades de melhoria associam-se a $20 \%$ das causas-potenciais (SANTOS \& MAURÍCIO, 2016).

Contudo, o objetivo da utilização do princípio de Pareto é direcionar a capacidade de solução disponível para as causas que tenham resultados maximizados a utilização dos recursos disponíveis mais eficiente, pois, a seleção de causas a serem priorizadas, posta de forma sistemática, possibilita a atenção gerencial aos problemas que ocasionam o maior número de desperdícios, isto é, as maiores fontes de variação no processo (Corrêa \& Corrêa, 2017).

\subsection{CARTAS DE CONTROLE}

Se apenas causas comuns de variação estão presentes no processo o resultado seguirá com estabilidade ao decorrer do tempo sendo fácil sua previsibilidade, porém, se as causas de variação são especiais o desfecho do processo será imprevisível, mas, a variável impactante será facilmente identificada (DeFOE \& JURAN, 2015)

O modelo genérico de um gráfico de controle de Shewhart possui uma representação sequencial de um indicador no tempo e, para que o processo seja considerável estável, os pontos devem variar dentro dos limites de controle de forma aleatória entre os desviospadrões, mas, variando pela média (SANTOS \& MAURÍCIO, 2016).

Para DeFoe \& Juran (2015) as grandes organizações que entendem a variabilidade nos seus processos-chaves e a controlam promoverem o aumento da confiabilidade e da qualidade percebida nos serviços entregando valor ao cliente (CORBETT, 2011).

\subsection{MILK RUN}

Para Nemoto \& Rothengatter (2012) o Milk Run é uma estratégia competitiva que sincroniza a redução dos custos logísticos de transporte com a velocidade de entrega dos pedidos gerando confiabilidade no processo produtivo como um todo em função de um planejamento integrado entre o comprador e o fornecedor baseados no Just In Time.

Rodrigues (2014) destaca que o Milk Run permite maior controle da gestão dos materiais, fluxo de informações, fluxo de abastecimento e o fluxo de circulação na unidade de negócio. Sua implantação exige a proximidade com os fornecedores, alinhamento com as especificações do material e disponibilização dentro da janela do planejamento para o veículo da empresa coletar o material no fornecedor.

\section{MÉTODOS DE PESQUISA}

Esta pesquisa pode ser classificada como exploratória, pois, este estudo tem por objetivo identificar o motivo da rejeição dos orçamentos da prestadora de serviços. Não obstante, pode-se classificar também sua natureza como qualitativa e quantitativa, uma vez que, busca entender o processo pelo seu fluxo de valor e as etapas desse fluxo são analisadas quantitativamente. O método utilizado foi estudo de caso único, devido a investigação profunda do problema e as ações tomadas sobre o objeto de estudo (YIN, 2015). 
O método de trabalho utilizado é apresentado em 7 etapas conforme a figura $2 \mathrm{com}$ base no modelo de Rother \& Shock (2004) para o desenvolvimento dos mapas de processo do fluxo de valor apresentado na figura 1:

\begin{tabular}{|l|l|}
\hline & •Análise do estado atual \\
\hline & •Contrução do MFV do estado atual \\
\hline & •Identificação da causa-potencial \\
\hline & •-Análise da causa-raiz \\
\hline & • Proposta de solução \\
\hline
\end{tabular}

Figura 3 - Fluxograma do método

Fonte: Autores (2019).

As etapas serão discutidas no estudo de caso a seguir onde será apresentada toda a linha de pesquisa e desdobramento das ações para atingir o resultado desejado pela empresa estudada, denominada de XYZ, com a utilização da metodologia Lean Manufacturing aplicada à gestão de serviços.

\section{ESTUDO DE CASO}

A Empresa XYZ refrigeração LTDA-ME é uma microempresa que atua na área de serviços e atualmente faz parte da rede de serviços autorizados de uma grande multinacional sueca, que será nomeada como WG, sendo também contratada por uma grande seguradora brasileira com o mesmo propósito do grupo WG: atender os clientes pós-venda do seguimento de linha branca.

Atualmente a empresa comporta 17 funcionários sendo eles três de nível tático enquanto os demais estão no nível operacional. A empresa é de cunho familiar e não utiliza linguagem técnica para alocação de atividades, logo, níveis como gerentes e supervisores estão no mesmo patamar enquanto operação e administrativos também são equivalentes.

\subsection{ANÁLISE DO ESTADO ATUAL}

A principal fonte de receita da empresa são os serviços prestados aos consumidores nas modalidades fora de garantia (FG), garantia estendida (GE) por contrato com a seguradora e os serviços em garantia $(G)$ dos produtos do fornecedor WG. As ordens de serviço fora de garantia representam o fluxo de caixa da empresa, enquanto a receita da garantia estendida é gerada por informativos financeiros recebidos periodicamente assim também é a garantia do fornecedor WG. O gráfico 1 a seguir expressa essa relação. 


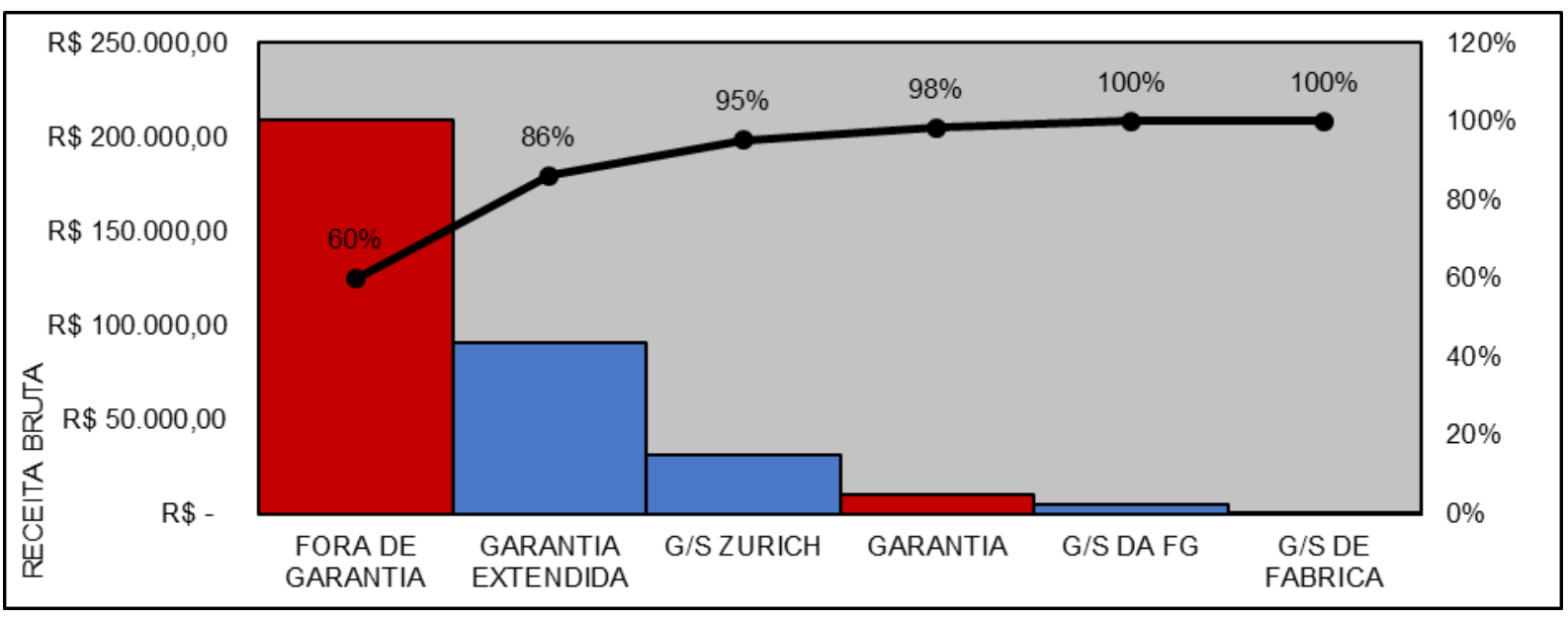

Gráfico 1 - Modalidade de serviços Fonte: Autores (2019).

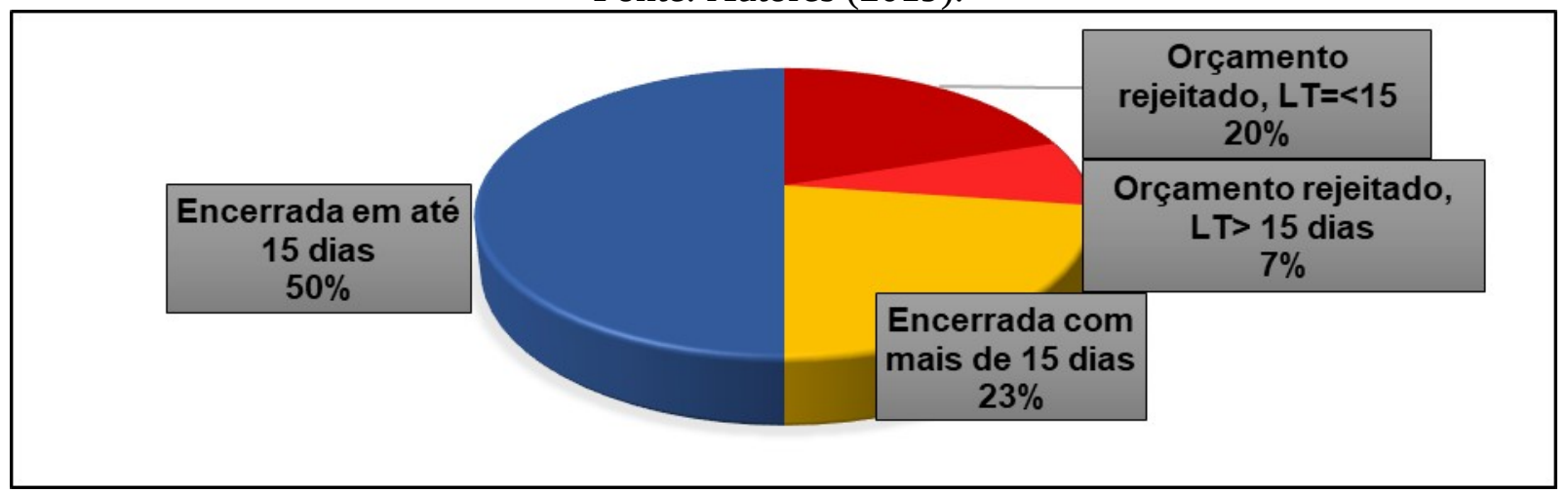

Ao analisar os dados disponíveis dos serviços verificou-se que o lead time das ordens de serviço fora de garantia (OS FG) tiveram $27 \%$ de seus orçamentos cancelados por falta de peça no estoque enquanto 23\% foram executadas com mais de 15 dias. Não obstante, 222 ordens de serviço foram finalizadas em 15 dias e isto demonstra que em $27 \%$ dos casos a voz do cliente implica no cancelamento dos serviços por falta de peça no estoque e em apenas $23 \%$ dos casos essa condição foi aceita pelo consumidor, conforme o gráfico 2 apresenta a seguir.

Gráfico 2 - Resultado dos serviços fora de garantia no segundo semestre de 2017.

Fonte: Autores (2019).

Observando o gráfico 2, no segundo semestre de 2017 a empresa foi capaz de atender metade das ordens de serviço em 15 dias, enquanto da outra metade apenas 23\% foram convertidos em receita resultando em um nível de serviço de $73 \%$ de rendimento correspondendo apenas a 50\% da métrica RTY. Para compreender o macroprocesso e identificar oportunidades para redução de desperdícios foi considerado apenas o fluxo das ordens de serviço que necessitam de pedidos para serem concluídas.

$\mathrm{Na}$ amostragem serão consideradas 75 ordens de serviços do período entre outubro e novembro, pois o objetivo deste mapeamento foi entender a demora na execução do serviço, identificar os possíveis gargalos do sistema para eliminar os desperdícios. Nota-se com no MFV (apêndice 1) que o lead time total da entrega do serviço foi de 25,68 dias para ordens de serviços que entraram no status aguardando e que em cerca de $80 \%$ do tempo o pedido estava sendo processado pelo fornecedor. O gráfico 3 estratifica os tempos das atividades que não agregam valor (conforme o apêndice 1): 


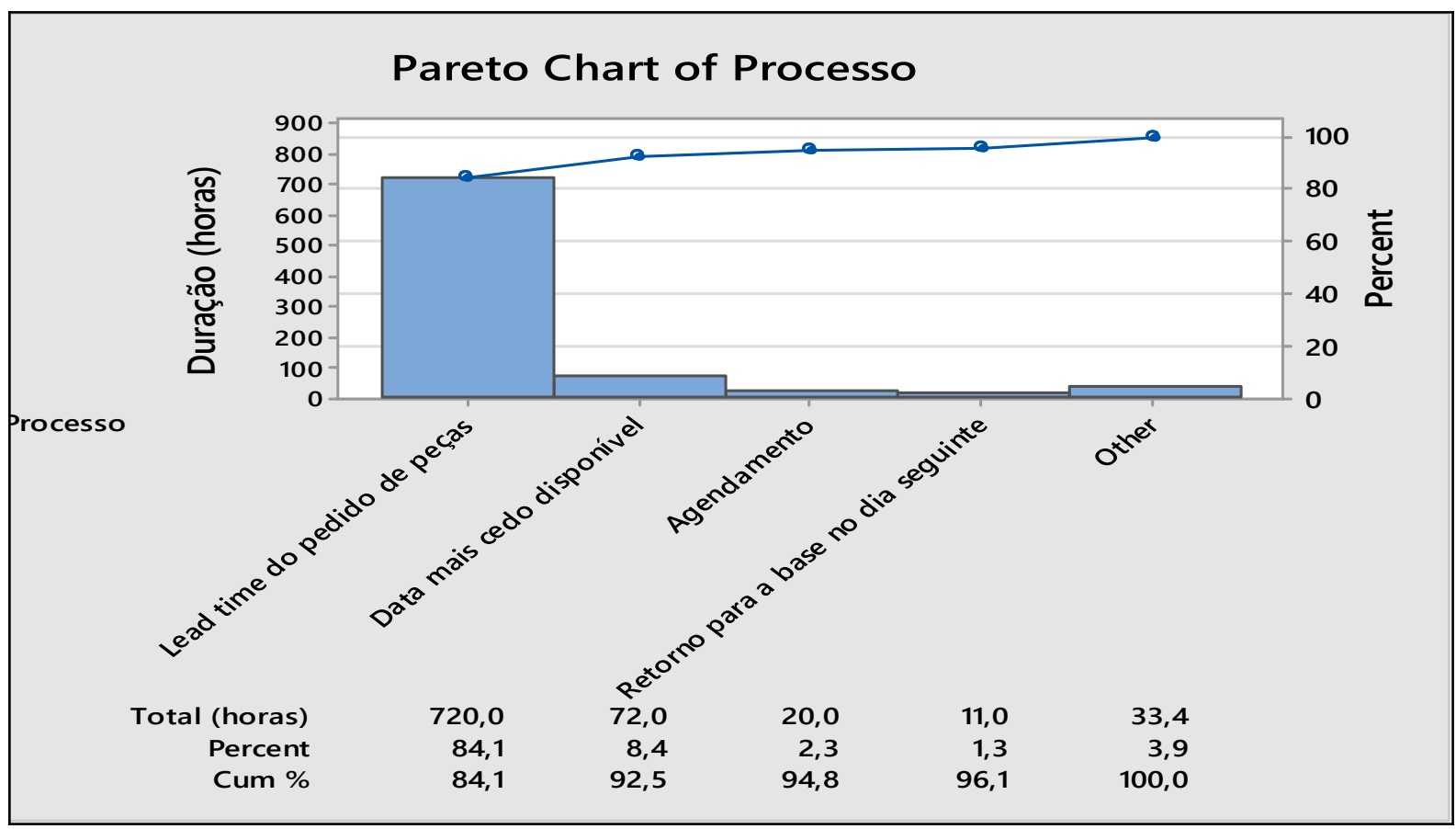

Gráfico 3 - Identificando as causas-potenciais

Fonte: Autores (2019).

Com o gráfico 3 pode-se analisar que:

- $94 \%$ de todo o lead time os clientes estão aguardando um novo agendamento do serviço caracterizando o desperdício de espera.

- $84 \%$ do lead time os pedidos estão sendo processados pelo fornecedor.

- O tempo que agrega valor é inferior a um dia e a eficiência do processo é na ordem de $0,03 \%$

- Este cenário aconteceu quando não havia disponibilidade no estoque, isto é, $50 \%$ das vezes no atendimento fora de garantia (gráfico 2) gerando estoque de serviços em processo aguardando a liberação de peça, sinalizando mais um desperdício na visão lean.

Após 20 dias, em média, as peças chegam e a operação tem um elevado processamento de serviços em um fluxo desordenado, já que, algumas atividades rotineiras são deixadas de lado para dar atenção ao volume de serviços a serem liberados.

Com a integração entre o MFV (apêndice 1) e gráfico de Pareto (gráfico 3) foi possível correlacionar a causa lead time de entrega elevado com o efeito do baixo rendimento de ordens de serviços fora de garantia (RTY de 50\%) afunilando o processo de investigação das causas-potenciais.

\subsection{ANÁLISE DO PROCESSO DE PEDIDOS}

Para analisar o processamento dos pedidos foram utilizados o fluxograma com mapeamento de variáveis junto com o tempo de cada atividade do processo. O processo se dá no estoque e é iniciado quando a OS chega para o colaborador colocar os pedidos de peça, conforme ilustra a figura 4: 


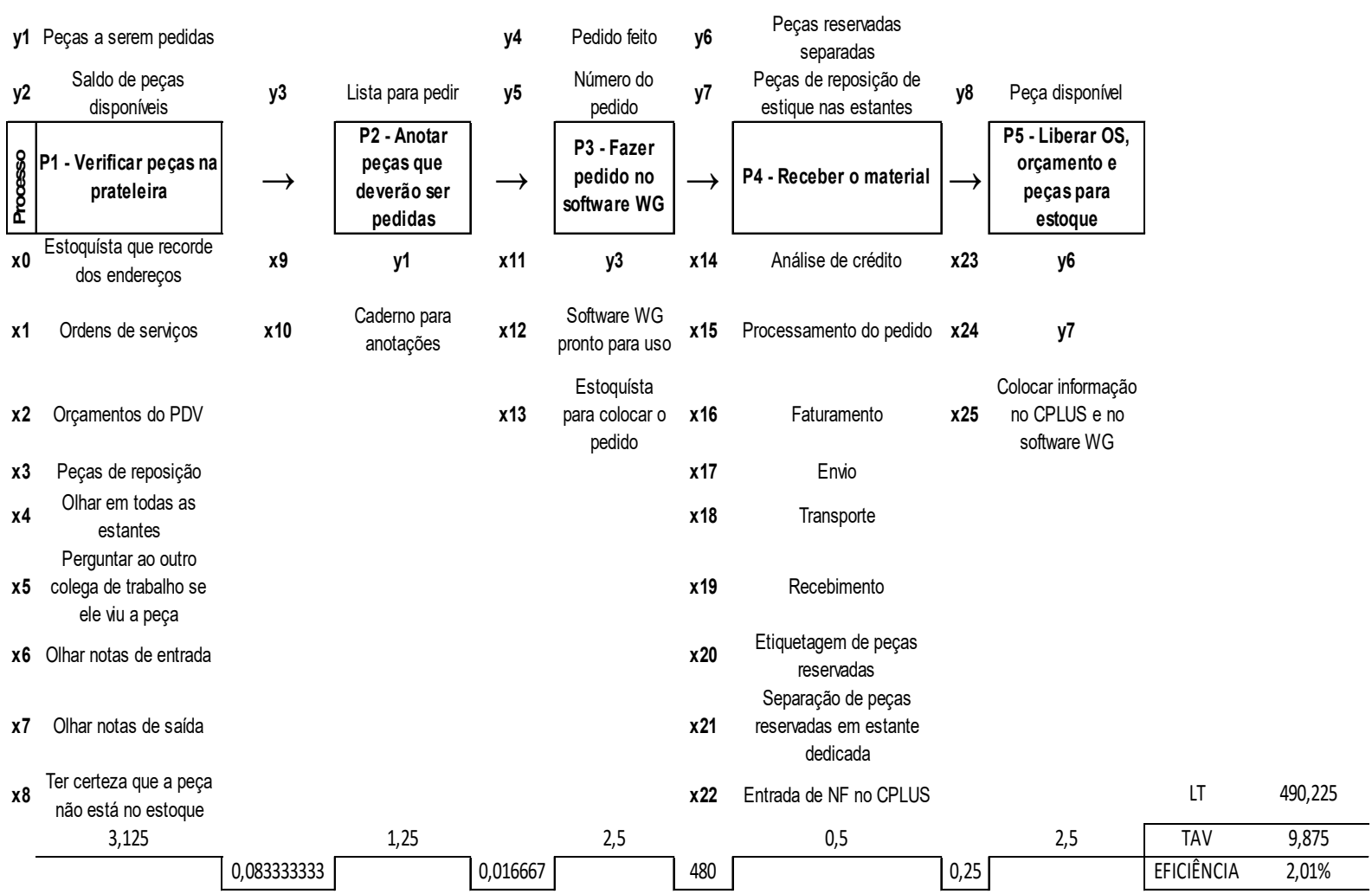

Figura 4 - Mapa do processo com identificação das variáveis

Fonte: Autores (2019).

Para analisar o lead time do processamento de pedidos (figura 4) foram separadas as variáveis que mais impactam o lead time do processo, cerca de 480h, que são o processamento do fornecedor (x14 a x17) e o tempo que a transportadora leva para entregar o pedido (x18). As análises dessas variáveis partem de registros disponíveis no software do fornecedor WG para colocação dos pedidos e em notas fiscais do período de novembro a dezembro de 2017 com 85 serviços analisadas.

Contudo, outras variáveis também poderiam determinar o comportamento do lead time dos serviços e para isto foi estratificado via banco de dados do software integrado da empresa o tempo que o setor de atendimento reagendava o serviço após o recebimento do pedido. Ao todo foram analisadas as seguintes variáveis: (i) LT de processos internos WG; (ii) LT de transporte; (iii) LT de agendamento; (iv) LT total do fornecedor.

Todos foram comparados entre si e com a duração das ordens de serviço. O teste realizado para trazer o entendimento do comportamento do serviço em função de sua variável explicativa foi o de correlação Pearson para identificar a relação das variáveis com lead time total do serviço. O resultado do teste é apresentado na figura 5: 


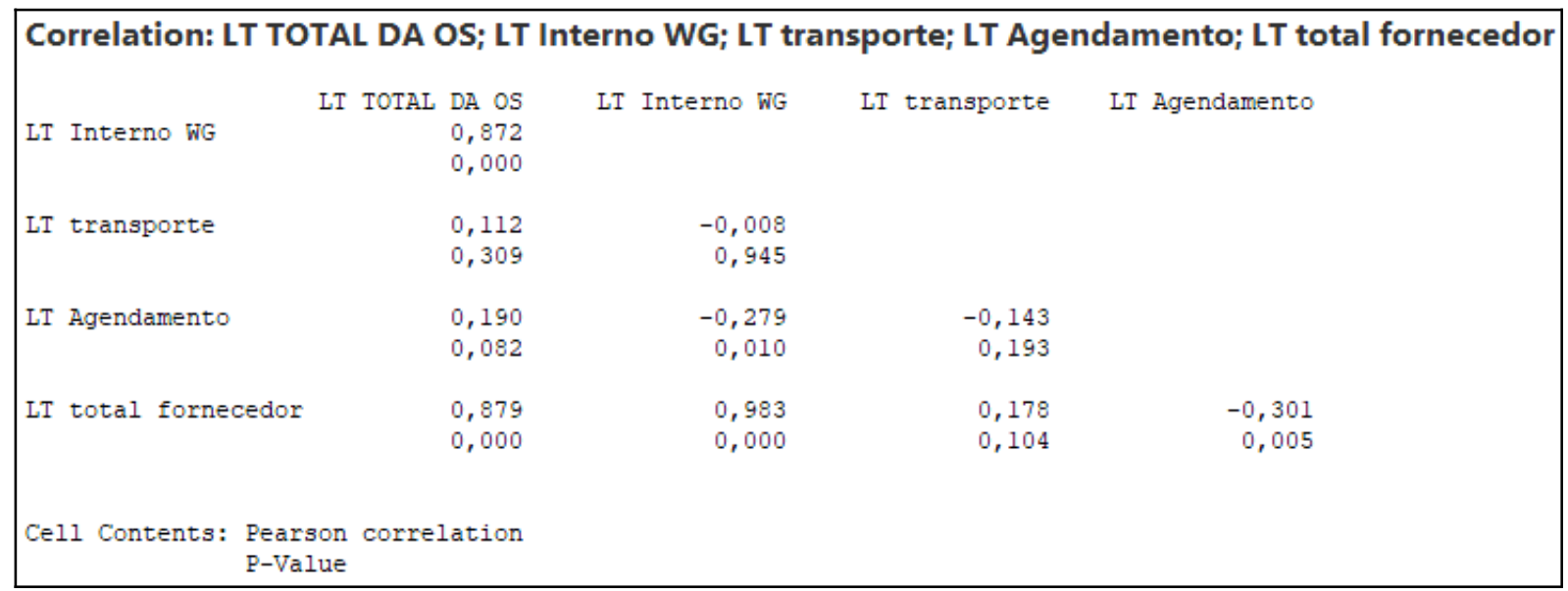

Figura 5 - Teste de correlação R-Pearson

Fonte: Autores (2019).

Analisando a figura 5 verifica-se que o LT interno do fornecedor e o processamento total dos pedidos têm forte correlação positiva com a duração dos serviços (p-value = 0,000, rejeita-se H0), porém, essas duas variáveis explicativas apresentam multicolinearidade e, por isso, será escolhida para o modelo de regressão linear apenas a variável de maior correlação com o lead time dos serviços. O gráfico 4 a seguir apresenta o modelo de regressão que relaciona o LT do processamento do fornecedor com o LT total do serviço:

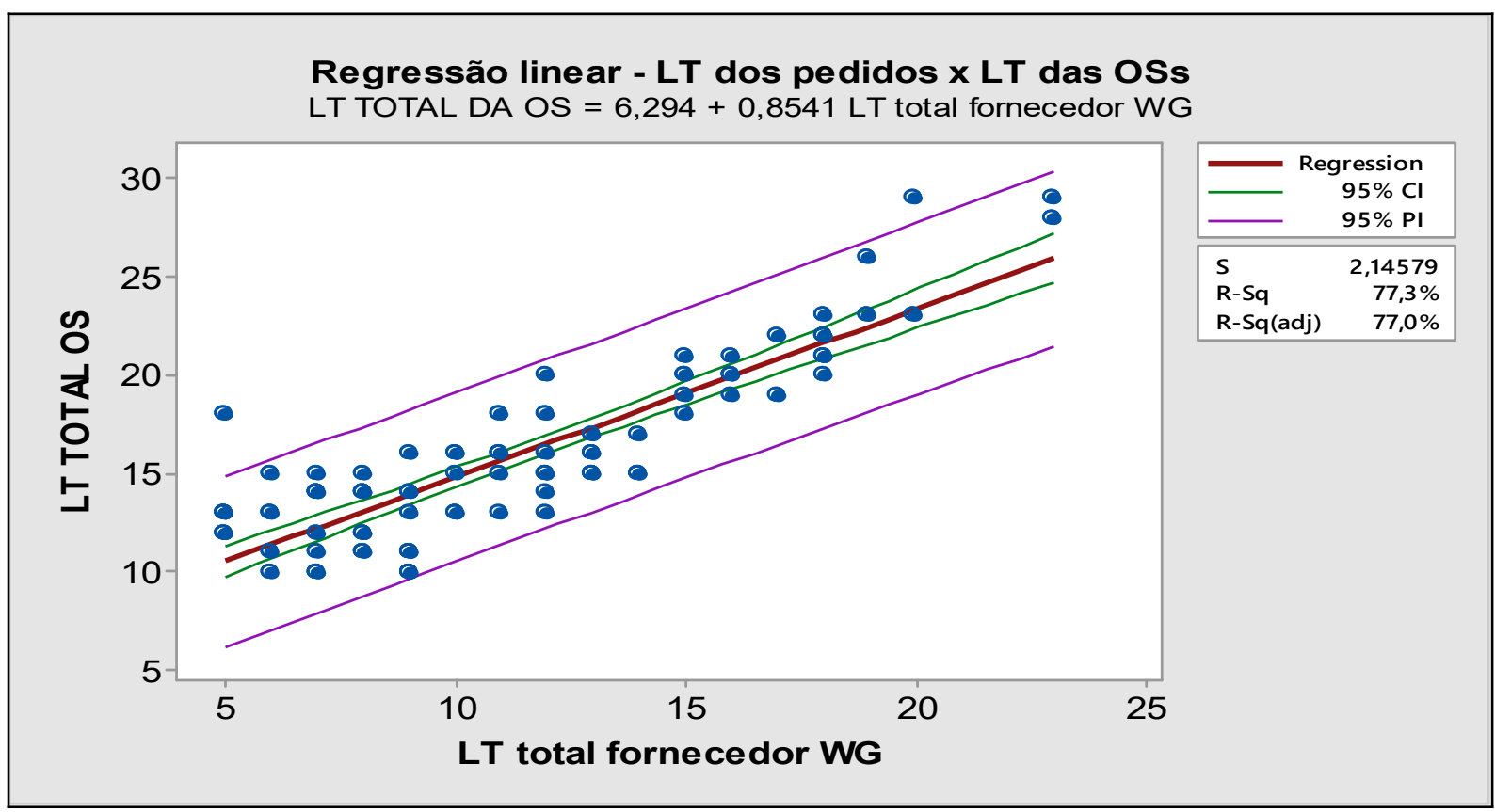

Gráfico 4 - Relação entre a variável explicativa e a duração dos serviços Fonte: Autores (2019).

O modelo representado no gráfico 4 possui $77 \%$ de aderência aos dados num intervalo de confiança de $95 \%$. Assim, a cada pedido colocado as ordens de serviço demoram seis dias a mais para serem finalizadas e cada dia de processamento do fornecedor acarreta mais 85\% desses dias na duração do serviço. Logo, há uma relação entre o processamento dos pedidos pelo fornecedor WG e a duração dos serviços prestado pela XYZ e isto impacta na aprovação dos serviços pelo cliente, reduzindo diretamente o fluxo de caixa da empresa quando se trata de serviços FG. 


\subsection{O MAPA DO ESTADO FUTURO DESEJADO}

Foi apresentada à equipe uma breve associação do lean thinking com a visão que a operação de serviços poderia assumir para traduzir seus atendimentos em valor para os clientes, identificando pontos a serem ajustados para potencializar o fluxo de valor para o cliente. A síntese é apresentada na tabela 2:

\begin{tabular}{|c|c|c|c|c|}
\hline \multicolumn{5}{|c|}{ Lean thinking aplicado a gestão dos serviços } \\
\hline Valor & Execução assertiva & Com a peça certa & No horário certo & $\begin{array}{c}\text { Com o atendimento } \\
\text { de qualidade }\end{array}$ \\
\hline $\begin{array}{l}\text { Fluxo de } \\
\text { valor }\end{array}$ & $\begin{array}{l}\text { Redução dos } \\
\text { desperdicios }\end{array}$ & $\begin{array}{l}\text { Velocidade na entrega } \\
\qquad \text { da peça }\end{array}$ & $\begin{array}{l}\text { Pontualidade no } \\
\text { atendimento }\end{array}$ & $\begin{array}{l}\text { Oferecer o melhor } \\
\text { serviço ao cliente }\end{array}$ \\
\hline $\begin{array}{c}\text { Fluxo } \\
\text { continuo }\end{array}$ & $\begin{array}{c}\text { Ter as peças certas no } \\
\text { estoque }\end{array}$ & $\begin{array}{l}\text { Manter o sincronismo } \\
\text { entre o fornecimento e } \\
\text { a demanda }\end{array}$ & $\begin{array}{l}\text { Manter a equipe } \\
\text { atualizada } \\
\text { profissionalmente }\end{array}$ & $\begin{array}{l}\text { Manter o fluxo de } \\
\text { informações } \\
\text { constante. }\end{array}$ \\
\hline Puxar & $\begin{array}{c}\text { O cliente puxa o } \\
\text { serviço pelos canais } \\
\text { de atendimento }\end{array}$ & $\begin{array}{l}\text { Pedir peças sem giro } \\
\text { apenas quando for } \\
\text { solicitado }\end{array}$ & $\begin{array}{l}\text { Desenvolver meios de } \\
\text { manter a equipe no } \\
\text { foco }\end{array}$ & $\begin{array}{l}\text { Respeitar a } \\
\text { capacidade de } \\
\text { entrega }\end{array}$ \\
\hline Perfeição & $\begin{array}{l}\text { Analisar os resultados } \\
\text { com indicadores } \\
\text { representativos }\end{array}$ & $\begin{array}{c}\text { Focar nas } \\
\text { necessidades dos } \\
\text { clientes }\end{array}$ & $\begin{array}{l}\text { Focar na velocidade } \\
\text { do processo e não } \\
\text { permitir a cultura do } \\
\text { desperdicio }\end{array}$ & $\begin{array}{l}\text { Manter parcerias } \\
\text { que resultem na } \\
\text { melhor experiência } \\
\text { para o consumidor }\end{array}$ \\
\hline
\end{tabular}

Tabela 2 - Associação do Lean thinking com a operação.

Fonte: Autores (2019).

A tabela 2 representa toda a estrutura baseada no lean para a prestação de serviços de excelência ao consumidor elevando o patamar da operação a níveis de maior satisfação. Notase que a integração do lean thinking com os processos da empresa torna a gestão do negócio voltada a qualidade de atendimento. Assim, este levantamento com a equipe serviu de base para que fosse possível enxergar melhor os desperdícios da operação e manter o fluxo de valor constante entre a operação e o cliente.

Foi proposto um estado intermediário para a execução dos serviços com base na negociação com novos fornecedores no Estado do Rio de Janeiro e utilização da ferramenta Milk Run. Com isto, a duração do serviço passaria a ser de três dias, pois, com o Milk Run a peça ficaria disponível no dia seguinte, após a primeira visita do técnico ao consumidor, reduzindo em 82\% (de 25 dias para 3 dias) o lead time dependendo apenas da disponibilidade dos fornecedores. Como pode ser observado na figura 6 : 


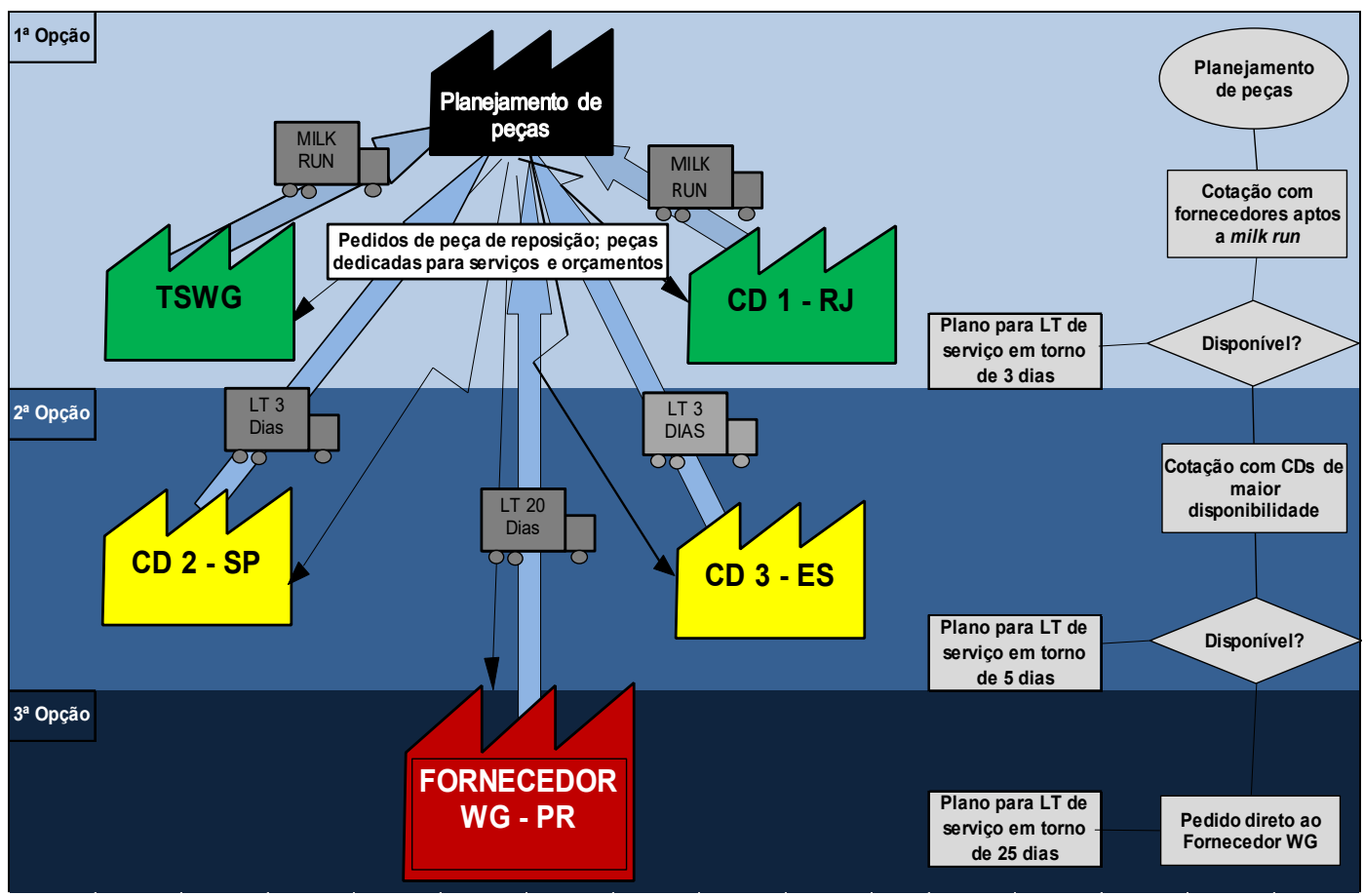

Figura 6 - Planejamento de peças e gestão de fornecedores

Fonte: Autores (2019).

Desta forma os pedidos serão atendidos em níveis: primeiro o distribuidor mais próximo, segundo os distribuidores em estados adjacentes e por último será cotado o fornecedor WG, levando em conta a passagem de nível em função da disponibilidade, conforme a figura 6 .

\subsection{AVALIAÇÃO DOS RESULTADOS}

A mudança de patamar é observada no gráfico 5 com a carta de controle com uma nova média em 3,98 dias de atendimento (diferença de onze dias com o estado passado) variando entre sete e zero dias.

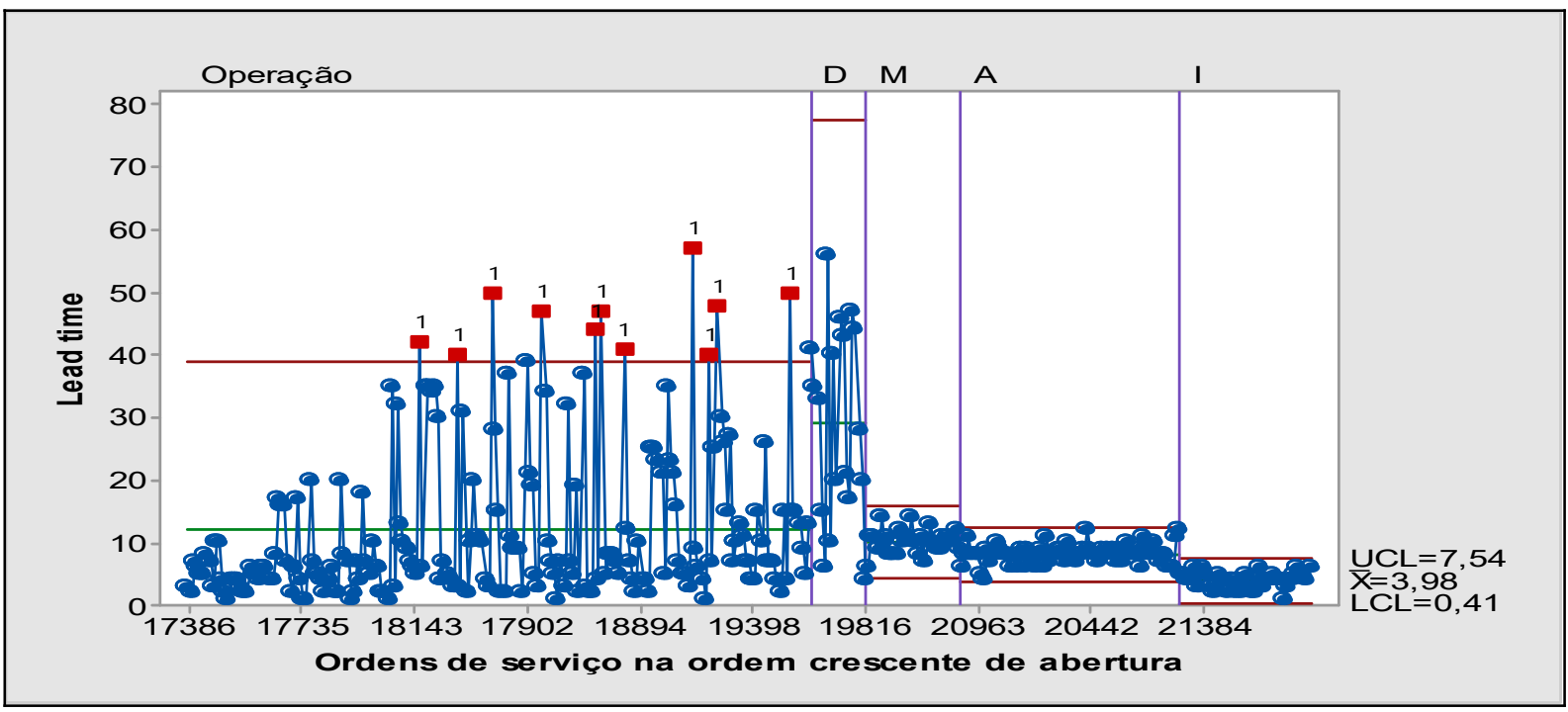

Gráfico 5 - Análise do lead time de encerramento

Fonte: Autores (2019).

Não obstante, a mudança no patamar do lead time provocou um aumento no indicador de rendimento global que antes representaram $50 \%$ dos atendimentos fora de 
garantia e após a mudança no processo chegou a 86\% (aumento de 36\%) contra 14\% de rejeição dos orçamentos, conforme o gráfico 6:

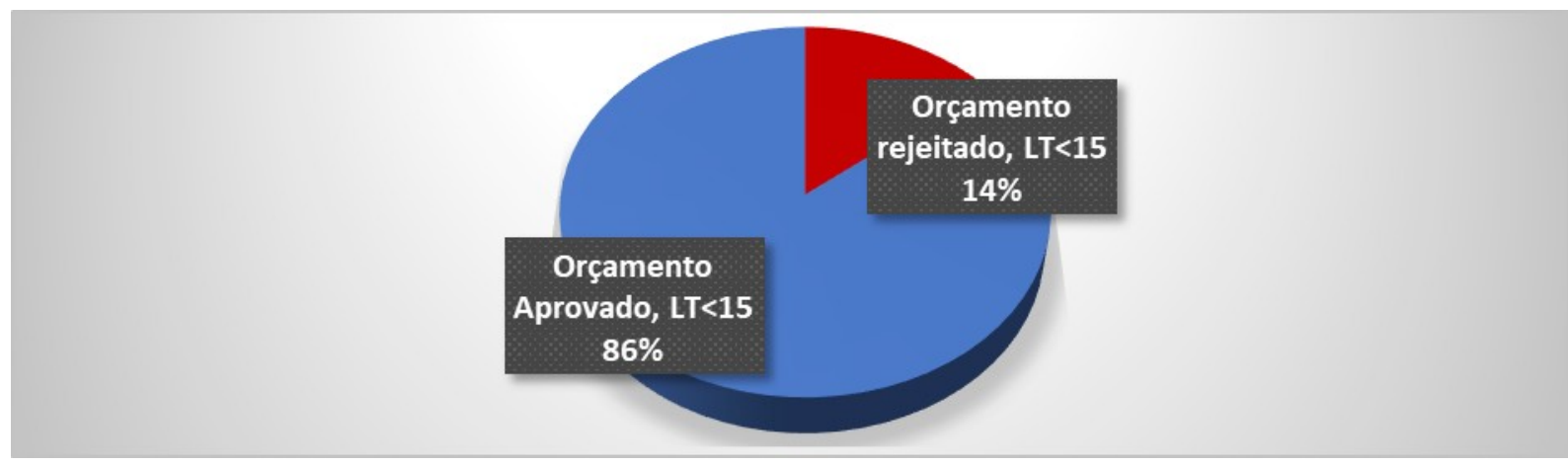

Gráfico 6 - Avaliação do RTY e orçamentos rejeitados na fase improve

Fonte: Autores (2019).

É importante ressaltar a crise política e econômica brasileira que correlacionam um desnível nos resultados de janeiro a fevereiro de 2018 comparados com o mesmo período em 2017. Só em janeiro a diferença esteve em 61\% comparando os volumes de serviço, já em fevereiro esta proporção subiu para 67\%. A diferença no lucro bruto obtido com os serviços chegou a 47\% do valor de 2017 para 2018. Essas informações indicam uma nova mudança no gargalo da empresa que passa a ser o mercado de serviços do fornecedor WG. Conforme ilustra o gráfico 7:

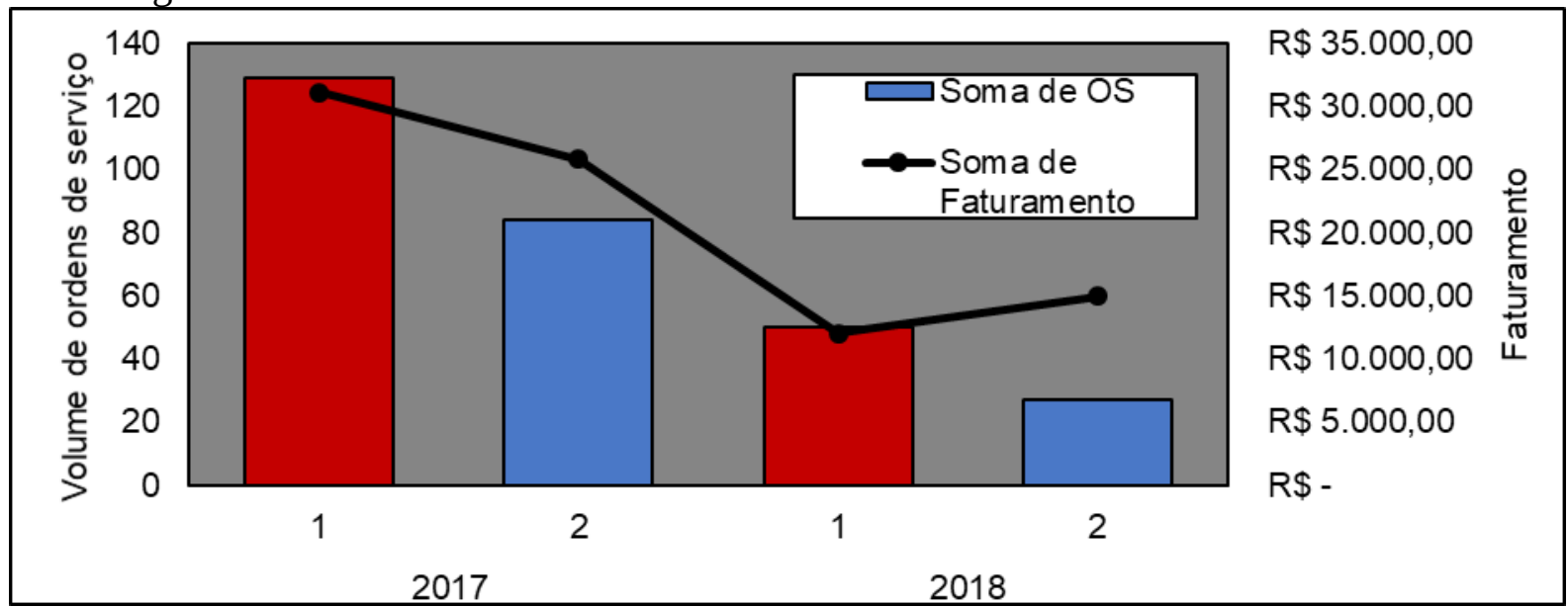

Gráfico 7 - Análise dos resultados comparando 2018 com 2017

Fonte: Autores (2019).

Embora a recessão tenha afetado a demanda dos serviços o lucro líquido da empresa teve crescimento em média de $25 \%$ com desvio padrão de $\mathrm{R} \$ 1567,35$ por mês e janeiro e fevereiro somados apresentaram 60\% do lucro num total de $\mathrm{R} \$ 24.803,43$ de receita no período do projeto de melhoria.

Até o fim do mês de fevereiro o faturamento cobriu todas as despesas estando com lucro líquido de 63\% disponível para empresa. A tabela 3 representa a síntese dos resultados obtidos com o projeto de melhoria no processo: 


\begin{tabular}{l|cccc}
\hline \multicolumn{1}{c|}{ Indicador } & Antes & Depois & Medida & Ganho \\
\hline Lead time médio dos serviços & 25 & 3,98 & dias & $84 \%$ \\
\hline Variabilidade do lead time dos serviços & 7 & 1,18 & dias & $83 \%$ \\
\hline Lead time médio dos pedidos & 20 & 1 & dias & $95 \%$ \\
\hline Variabilidade do lead time dos pedidos & 5 & 0,8 & dias & $84 \%$ \\
\hline Tempo que agrega valor & 0,76 & 0,76 & dias & $0 \%$ \\
\hline Eficiência do processo & $0,03 \%$ & $20 \%$ & dias & $66567 \%$ \\
\hline Rendimento & $73 \%$ & $86 \%$ & OS FG & $15 \%$ \\
\hline RTY & $50 \%$ & $86 \%$ & OS FG & $42 \%$ \\
\hline Orçamentos rejeitados & $27 \%$ & $14 \%$ & OS FG & $48 \%$ \\
\hline OS encerradas com lead time s uperior a $\mathbf{1 5}$ dias & $23 \%$ & $0 \%$ & OS FG & $100 \%$ \\
\hline OS encerradas com lead time inferior ou igual a $\mathbf{1 5}$ dias & $50 \%$ & $100 \%$ & OS FG & $50 \%$ \\
\hline
\end{tabular}

Tabela 3 - Síntese dos resultados obtidos com a melhoria no processo

Fonte: Autores (2019).

Nota-se com a tabela 3 que os indicadores de performance do processo foram amplamente atingidos pela melhoria apresentando resultados significativos, com o destaque para a eficiência do processo que passou de $0,03 \%$ para $20 \%$ de todo o lead time do serviço (66567 vezes o estado anterior), assim como o próprio lead time que teve uma redução próxima a $84 \%$ na média e de $83 \%$ na variabilidade, assim, conclui-se que os objetivos traçados foram alcançados.

\section{CONCLUSÃO E PROPOSTA PARA TRABALHOS FUTUROS}

O objetivo deste projeto foi atingido ao reduzir o lead time dos serviços da empresa XYZ utilizando o Lean Manufacturing. Com base nos resultados obtidos, houve aderência no uso da metodologia, mesmo numa operação fora do contexto industrial. É importante destacar a relevância e a aplicabilidade do Lean no ambiente de serviços, proporcionando efetividade através da aplicação da sua estrutura de análise de processos e solução de problemas.

A medição do lead time e a da taxa de saída contribuíram para o fluxo de valor, possibilitando que a causa-raiz do problema - que era a relação entre o processamento do fornecedor e o lead time do serviço - tivesse sido identificada e tratada com a mudança no processo de pedidos e a utilização do Milk Run.

Fica como proposta para futuros trabalhos a tratativa dos retrabalhos, que são chamados de garantia de serviços já executados, devido ao alto índice identificado no gráfico 1 que representaram cerca de 20\% de todos os atendimentos feitos de 2017.

\section{REFERÊNCIAS BIBLIOGRÁFICAS}

[1] CAMPOS, V. Falconi. TQC: Controle da Qualidade Total no Estilo japonês. 9 Ed. Editora: Atlas, 2014.

[2] CORBETT, L. M. Lean Six Sigma: the contribution to business excellence. International Journal of Lean Six Sigma, 2 (2), 118-131, 2011.

[3] CORRÊA, Henrique L. CORRÊA, Carlos A. Administração da produção e operações manufatura e serviços: uma abordagem estratégica. São Paulo. Atlas. 2017.

[4] COSTA R.S. e JARDIM E.G.M. - OS CINCO PASSOS DO PENSAMENTO ENXUTO NET, Rio de Janeiro, 2010. Disponível em: http://www.trilhaprojetos.com.br. 
[5] DeFEO, Joseph A.; JURAN, Joseph M. Fundamentos da qualidade para líderes. São Paulo: Bookman, 2015.

[6] GIBBONS, Paul M.; BURGESS, Stuart C.; Introducing OEE as a measure of lean Six Sigma capability, International Journal of Lean Six Sigma, Vol. 1 Iss: 2 pp. 134 156, 2010. Disponível em: http://dx.doi.org/10.1108/20401461011049511. Acesso em 01/05/2018.

[7] GUIMARÃES, L.A. e GUIMARÃES, C.R. Utilização da construção enxuta no planejamento e controle de obras na construção civil. João Pessoa: XXXVI Encontro Nacional de Engenharia de Produção (ENEGEP), 2016.

[8] LACERDA, António Pedro.; XAMBRE, Ana Raquel1.; ALVELOS, Helena Maria.; Applying Value Stream Mapping to eliminate waste: a case study of an original equipment manufacturer for the automotive industry. International Journal of Production Research., Vol. 54 Issue 6, p1708-1720. 13p. 2016. Disponível em: http://web.b.ebscohost.com/ehost/pdfviewer/pdfviewer?vid=1\&sid=c2260e1c-4c4b41ec-840f-c381e35386d9\%40sessionmgr104. Acesso em 23/04/2018.

[9] FAST, Larry.; More 'Must Have' Metrics to Drive Continuous Improvement. Industry. Week, Nov 15, 2016. Disponível em: http://www.industryweek.com/moremust-have-metrics Acesso em 01/05/2018.

[10] LIKER, J. K. O modelo Toyota. 14 princípios do maior fabricante do mundo. Porto Alegre: Bookman, 2005.

[11] NEMOTO, Toshinori.; ROTHENGATTER, Werner.; Efficient Green Logistics in Urban Areas: Milk Run Logistics in the Automotive Industry, in Roger L. Mackett, Anthony D. May, Masanobu Kii, Haixiao Pan (ed.) Sustainable Transport for Chinese Cities (Transport and Sustainability, Volume 3) Emerald Group Publishing Limited, pp.319 - 337. 2012.

[12] OHNO, Taiichi. O Sistema Toyota de produção. Porto Alegre: Bookman, 1997.

[13] PIAZZA, Micael; CECCONELLO, Ivandro; VIDOR, Gabriel. Aplicação da ferramenta mapeamento do fluxo de valor em uma célula de produção de uma empresa do ramo de plástico. João Pessoa: XXXVI Encontro nacional de Engenharia de Produção (ENEGEP), 2016.

[14] RODRIGUES, Marcus Vinícius.; Entendendo, aprendendo e desenvolvendo: Sistema de produção Lean Manufacturing, Rio de Janeiro: Elsevier, 2014.

[15] SANTOS, Isis Barros; MAURICIO, Thiago Buselato. Aplicação de ferramentas da qualidade para análise e solução de rupturas em um processo de admissão de estagiários. João Pessoa: XXXVI Encontro nacional de engenharia de produção (ENEGEP), 2016.

[16] SLACK, Nigel. BRANDON-JONES, Alistair. JOHNSTON, Robert. Administração da Produção. 4 Ed. São Paulo: Editora Atlas. 2015.

[17] SNEE, R. D. Lean Six Sigma: getting better all the time. International Journal of Lean Six Sigma, 1 (1), 9-29, 2010.

[18] WERKEMA, Cristina. Lean Seis Sigma: Introdução às Ferramentas do Lean Manufacturing. Belo Horizonte: Werkema, 2006.

[19] WOMACK; J. P.; JONES, D. T; ROSS, D. A máquina que mudou o mundo. Elsevier, 
Rio de Janeiro, 1990.

[20] WOMACK, James P.; JONES, Daniel T. A mentalidade enxuta nas empresas: Elimine o desperdício e crie riqueza. Rio de Janeiro: Elsevier, 2004. 